\title{
Inflammatory response after inhalation of bacterial endotoxin assessed by the induced sputum technique
}

\author{
Jörgen Thorn, Ragnar Rylander
}

\begin{abstract}
Background-Organic dusts may cause inflammation in the airways. This study was performed to assess the usefulness of the induced sputum technique for evaluating the presence of airways inflammation using inhaled endotoxin (lipopolysaccharide) as the inducer of inflammation.

Methods-To characterise the inflammatory response after inhalation of endotoxin, 21 healthy subjects inhaled $40 \mu \mathrm{g}$ lipopolysaccharide and were examined before and 24 hours after exposure. Examinations consisted of a questionnaire for symptoms, spirometric testing, blood sampling, and collection of induced sputum using hypertonic saline. Eleven of the subjects inhaled hypertonic saline without endotoxin exposure as controls. Cell counts, eosinophilic cationic protein (ECP), and myeloperoxidase (MPO) were determined in blood and sputum.
\end{abstract}

Results-A significantly higher proportion of subjects reported respiratory and general symptoms after endotoxin inhalation. MPO and the number of neutrophils in the blood were higher and spirometric values were decreased after the lipopolysaccharide challenge. In the sputum MPO, ECP, and the numbers of neutrophils and lymphocytes were higher after the lipopolysaccharide challenge. No significant differences were found after the inhalation of hypertonic saline compared with before, except for a significantly lower number of lymphocytes in the sputum.

Conclusions-The results support previous studies that inhaled endotoxin causes an inflammation at the exposure site itself, as well as general effects. Sampling of sputum seems to be a useful tool for assessing the presence of airways inflammation, and the inhalation of hypertonic saline used to induce sputum did not significantly interfere with the results found after inhalation of lipopolysaccharide.

(Thorax 1998;53:1047-1052)

Keywords: endotoxin; airways inflammation; inflammatory markers

Received 16 March 1998 Returned to author 8 May 1998

Revised manuscript received

12 August 1998

Accepted for publication

20 August 1998
There is increasing evidence that diseases and symptoms caused by organic dusts are mainly of an inflammatory nature. A previous analysis of the symptoms present after exposure to cotton dust (byssinosis) revealed characteristics related to an inflammation in the airways such as dry cough, narrowing of the airways after an acute exposure, and increased airway responsiveness. ${ }^{1}$

Among the many agents present in organic dusts there is substantial evidence to suggest that bacterial endotoxin is a major causative agent. Several symptoms observed after exposure to organic dust have been related to the content of endotoxin in a dose-response fashion, and a relation between the amount of endotoxin in grain dust and airway responsiveness has been reported. ${ }^{2}$ A relationship has been found between humidifiers contaminated with Gram negative bacteria/endotoxin and inhalation fever (toxic pneumonitis). ${ }^{3}$ Guidelines for exposure to airborne endotoxin in the environment have been suggested. ${ }^{4}$

Of particular interest for causality are studies in which the pure agent is administered to human subjects. For ethical reasons, such exposures are limited to single inhalations. Previous investigations in which healthy subjects inhaled pure endotoxin (lipopolysaccharide, LPS) showed a decrease in forced expiratory volume in one second $\left(\mathrm{FEV}_{1}\right)$ and an increase in reported symptoms such as chest tightness and airway irritation, fever, headache, joint and muscle pains, nausea and tiredness after the inhalation. ${ }^{5} \mathrm{~A}$ decrease in carbon monoxide transfer factor after inhalation of LPS has been reported, ${ }^{6}$ as well as increased airway responsiveness among asthmatic subjects. ${ }^{7}$ The cellular inflammatory response after inhalation of LPS was studied in bronchoalveolar lavage fluid where an increase in neutrophils, lymphocytes and fibronectin was reported, ${ }^{8}$ and in blood where an increase in the number of neutrophils and $\mathrm{C}$ reactive protein (CRP) was observed. ${ }^{9}$ An increase in the numbers of neutrophils and lymphocytes, and in levels of myeloperoxidase (MPO) and eosinophilic cationic protein (ECP) has been found in induced sputum after inhalation of LPS. $^{10}$

The purpose of this study was to assess the inflammatory response after LPS inhalation and to compare the effect in two different compartments, blood and induced sputum. The induced sputum technique requires inhalation of hypertonic saline. As this could theoretically influence the response to LPS, a separate experiment on the effects of inhaled hypertonic saline was performed. Respiratory and general symptoms were assessed using a questionnaire. 


\section{Methods}

SUBJECTS

The study group comprised 21 healthy subjects (nine men) recruited from students at the local university. The mean age was 25 years (range 20-30 years). Potential subjects were interviewed using a standard questionnaire and those accepted in the study were never smokers, had no current colds, no self-reported allergy, no chronic bronchitis or physician diagnosed asthma. They were also non-atopic as defined by a negative reaction in the Phadiatop test. ${ }^{11}$

STUDY DESIGN

The subjects inhaled $40 \mu \mathrm{g}$ LPS and were examined before the exposure and 24 hours afterwards. Examinations consisted of spirometric tests and collection of blood and induced sputum samples. Differential cell counts, ECP, and MPO were determined in blood and sputum. A questionnaire was used to identify symptoms.

Of the 21 subjects, 11 (three men) also inhaled hypertonic saline (5\%) alone as used in the induced sputum technique. They were also examined before the exposure and 24 hours afterwards. The washout period between LPS inhalation and inhalation of hypertonic saline alone was three months.

The study was approved by the ethics committee of the Faculty of Medicine in Gothenburg.

INHALATION OF ENDOTOXIN

Endotoxin (Escherichia coli LPS 026:B6 Difco) was suspended in saline and aerosolised using a Pari Boy nebuliser with automatic dosing. The nebuliser was calibrated and the automatic output adjusted to give $4 \mu \mathrm{l}$ per dose. The subject exhaled, placed the nebuliser in the mouth, and started to inhale. Each subject inhaled 20 puffs of endotoxin $(500 \mu \mathrm{g} / \mathrm{ml})$, up to a total of $40 \mu \mathrm{g}$.

DIFFERENTIAL CELL COUNTS IN BLOOD

Blood samples were collected for serum measurements and differential cell counts in blood using standard techniques. The results were expressed as $10^{9}$ cells $/ 1$ blood.

\section{INDUCED SPUTUM}

Sputum induction was performed according to the method of Pin et al ${ }^{12}$ with some modifications. Five percent saline was nebulised using an ultrasonic nebuliser (Fisoneb, Fisons, France) on the maximum setting and was inhaled initially for 10 minutes and then in five minute periods over a period of 20 minutes. Ten minutes after the start of nebulisation and every five minutes thereafter, subjects interrupted the inhalation of hypertonic saline and were asked to rinse their mouth and throat carefully and to try to cough sputum into a sterile plastic container. The nebulisation was discontinued after 20 minutes. The total amount of hypertonic saline administered was $20 \mathrm{ml}$.

For safety reasons, spirometric tests were performed before and immediately after spu- tum induction, using standard techniques, and the highest values for $\mathrm{FEV}_{1}$ and forced vital capacity (FVC) were registered and compared with predicted values. ${ }^{13}$ If the $\mathrm{FEV}_{1}$ decreased by more than $10 \%$ from the baseline value after sputum induction, a $\beta_{2}$ agonist was given by inhalation. One subject could not perform the spirometric tests after the challenge with LPS owing to her study schedule.

The volume of the collected sputum sample was determined and an equal volume of Sputasol (Oxoid; Unipath LTD, Basingstoke, Hampshire, UK) was added to obtain a final concentration of $325 \mathrm{mM}$ dithiothreitol (DTT). This concentration was used in the first five samples and then decreased to $3.25 \mathrm{mM}$ DTT to increase the number of intact cells. The samples were incubated in a shaking water bath at $37^{\circ} \mathrm{C}$ for $5-10$ minutes to ensure complete homogenisation. The samples were transferred into tubes and centrifuged at $600 \mathrm{~g}$ for five minutes. The supernatants were aspirated and frozen at $-70^{\circ} \mathrm{C}$ for later determination of ECP and MPO concentrations. The cell pellets were washed twice in a washing solution (Hank's salt solution $+5 \%$ fetal calf serum $+2 \%$ EDTA, adjusted to $\mathrm{pH} 7.2$ ). The total cell count and the cell viability were determined using a Bürker chamber and trypan blue exclusion. The cell samples were cytocentrifuged and two investigators each counted at least 200 nonsquamous cells on each slide fixed with methanol and stained with May-Grünwald-Giemsa. A cell sample was considered adequate if, on differential cell counting, it contained less than $50 \%$ squamous epithelial cells. The results were expressed as $10^{9}$ cells $/ 1$ sputum.

In the LPS inhalation experiment five samples containing more than $50 \%$ squamous epithelial cells were excluded from the analyses. A further five samples were excluded for technical reasons (see above).

INFLAMMATORY MARKERS

ECP was assayed in serum and sputum samples by a fluorescent enzyme immunoassay technique (CAP ECP FEIA, Pharmacia Diagnostics AB, Uppsala, Sweden) and expressed as $\mu \mathrm{g} / \mathrm{l}$. Prior to the analyses, cell free sputum samples were treated with equal volumes of $0.4 \%$ cetyltrimethylammonium bromide (CTAB; Calbiochem) diluted in $0.25 \%$ phosphate buffered saline and incubated at room temperature for one hour. After centrifugation at $1500 \mathrm{~g}$ for 10 minutes the supernatants were aspirated and used for ECP determinations. CTAB was used to neutralise the electrical forces in the ECP in order to optimise the FEIA analyses.

MPO was assayed in serum and sputum samples by a radioimmunoassay technique (CAP MPO RIA, Pharmacia Diagnostics AB, Uppsala, Sweden) and expressed as $\mu \mathrm{g} / 1$.

QUESTIONNAIRE

The subjects were interviewed using a slightly modified standard questionnaire for the assessment of organic dust induced effects. ${ }^{14}$ The questionnaire contained questions on cough (dry or with phlegm), chest tightness, shortness 
Table 1 Mean (SD) values of inflammatory markers and numbers of cells $\left(\times 10^{9} / \mathrm{l}\right)$ in blood before and 24 hours after inhalation of $40 \mu \mathrm{g}$ lipopolysaccharide (LPS) or hypertonic saline

\begin{tabular}{lllll}
\hline & & Before & After & Difference (95\% CI) \\
\hline LPS: & & & & \\
& & & & \\
ECP $(\mu \mathrm{g} / \mathrm{l})$ & & $\mathrm{n}=21$ & $\mathrm{n}=21$ & \\
MPO $(\mu \mathrm{g} / \mathrm{l})$ & & $7.2(4.6)$ & $8.3(4.0)$ & $-1.2(-3.2$ to 0.9$)$ \\
Eosinophils & $\mathrm{n}$ & $0.19(0.10)$ & $0.15(0.09)$ & $-123(-182$ to -63$)$ \\
& $\%$ & 2.8 & $1.8^{\star \star}$ & $0.04(0$ to 0.08$)$ \\
Lymphocytes & $\mathrm{n}$ & $2.87(0.86)$ & $2.69(0.95)$ & $0.2(-0.4$ to 0.8$)$ \\
& $\%$ & 41.6 & $27.3^{\star \star \star}$ & $14.2(10.4$ to 18.0$)$ \\
Monocytes & $\mathrm{n}$ & $0.45(0.30)$ & $0.44(0.23)$ & $0.01(-0.10$ to 0.12$)$ \\
& $\%$ & 6.2 & $4.5^{\star \star}$ & $1.7(0.6$ to 2.8$)$ \\
Neutrophils & $\mathrm{n}$ & $3.47(1.25)$ & $6.79(2.31)^{\star \star \star}$ & $-3.3(-4.3$ to -2.3$)$ \\
& $\%$ & 49.4 & $66.7^{\star \star \star}$ & $-17.2(-21.3$ to -13.2$)$ \\
Hypertonic saline: & & & & \\
& & $\mathrm{n}=11$ & $\mathrm{n}=11$ & \\
ECP $(\mu \mathrm{g} / \mathrm{l})$ & & $9.1(5.5)$ & $8.8(4.6)$ & $0.3(-0.8$ to 1.5$)$ \\
MPO $(\mu \mathrm{g} / \mathrm{l})$ & & $204(100)$ & $201(71)$ & $3(-30$ to 36$)$ \\
Eosinophils & $\mathrm{n}$ & $0.17(0.08)$ & $0.18(0.10)$ & $-0.01(-0.06$ to 0.05$)$ \\
& $\%$ & 2.9 & 3.0 & $-0.07(-1.0$ to 0.8$)$ \\
Lymphocytes & $\mathrm{n}$ & $2.58(0.75)$ & $2.36(0.60)$ & $0.2(-0.2$ to 0.7$)$ \\
& $\%$ & 41.7 & 39.6 & $2.2(-2.8$ to 7.1$)$ \\
Monocytes & $\mathrm{n}$ & $0.30(0.19)$ & $0.29(0.16)$ & $0.01(-0.09$ to 0.11$)$ \\
& $\%$ & 4.9 & 4.8 & $0.1(-1.4$ to 1.6$)$ \\
Neutrophils & $\mathrm{n}$ & $3.10(0.83)$ & $3.30(1.37)$ & $-0.2(-1.1$ to 0.7$)$ \\
& $\%$ & 50.6 & 52.8 & $-2.2(-7.6$ to 3.3$)$ \\
\hline
\end{tabular}

$\mathrm{ECP}=$ eosinophilic cationic protein; $\mathrm{MPO}=$ myeloperoxidase.

${ }^{\star \star} \mathrm{p}<0.01 ;{ }^{\star \star \star} \mathrm{p}<0.001$

of breath, irritation in the eyes, nose or throat, and nose congestion and itchy nose. Questions were also posed on joint pains, muscle pains, headache, unusual tiredness, skin problems, nausea, and diarrhoea.

ANALYSIS OF DATA

The differences between effect variables before and 24 hours after the exposure were analysed using non-parametric tests (Wilcoxon's and McNemar's tests) and paired samples tests. The relationship between continuous variables was analysed using a bivariate correlation test (Spearman). Differences were considered statistically significant at a level of $\mathrm{p}<0.05$.

\section{Results}

INFLAMMATORY MARKERS AND CELLS IN BLOOD The results of the determinations of markers for inflammation and cells in the blood are shown in table 1 . The amount of MPO was significantly greater after the inhalation of LPS than before. The amount of ECP was slightly greater after the inhalation but the difference was not statistically significant. The number of neutrophils was significantly higher after the inhalation of LPS than before. There was a significant relationship between levels of ECP and MPO before $\left(r_{x y}=0.54 ; \mathrm{p}=0.01\right)$ but not after inhalation of LPS $\left(r_{\mathrm{xy}}=0.04 ; \mathrm{p}=0.85\right)$. A statistically significant relationship was observed between the difference (before-after inhalation of LPS) in the number of neutrophils and the difference in MPO levels $\left(r_{\mathrm{xy}}=0.74\right.$; $\mathrm{p}<0.001)$. The ratio of MPO to neutrophils was significantly decreased after the inhalation of LPS compared with before (49 versus $64 \mu \mathrm{g} /$ neutrophil, $\mathrm{p}=0.002$ ).

Inhalation of hypertonic saline alone did not induce any significant changes in the inflammatory markers or in the numbers of different cells in the blood.

\section{INFLAMMATORY MARKERS AND CELLS IN} INDUCED SPUTUM

The results of the determinations of markers for inflammation and cells in induced sputum are shown in table 2. The amounts of ECP and MPO were significantly greater after the inhalation of LPS than before. The increase in MPO was almost threefold compared with the increase in blood of about $50 \%$. The numbers of neutrophils and lymphocytes were significantly higher after the inhalation of LPS. There was a significant relationship between the difference (before-after inhalation of LPS) in levels of ECP and MPO ( $\left.r_{\mathrm{xy}}=0.80 ; \mathrm{p}=0.003\right)$. There was also a significant relationship between MPO levels and the number of neutrophils after the inhalation of LPS $\left(r_{\mathrm{xy}}=\right.$ $0.80 ; \mathrm{p}=0.003)$. The ratio of $\mathrm{MPO}$ to neutrophils was significantly decreased after the inhalation of LPS compared with before (1738 versus $3340 \mu \mathrm{g} /$ neutrophil, $\mathrm{p}=0.03$ ).

There were no significant differences 24 hours after the inhalation of hypertonic saline alone, compared with the first occasion, except for the number of lymphocytes which was significantly decreased. With regard to the amounts of MPO and ECP, the standard deviations were high and there were two subjects and one subject, respectively, with much higher values both before and after the inhalation compared with the others. Analyses performed on nine and 10 subjects for amounts of MPO and ECP, respectively, showed no significant differences 24 hours after inhalation

Table 2 Mean (SD) amount of inflammatory markers and number of cells $\left(\times 10^{9} / l\right)$ in induced sputum before and 24 hours after inhalation of $40 \mu \mathrm{g}$ lipopolysaccharide (LPS) or hypertonic saline

\begin{tabular}{|c|c|c|c|c|c|c|}
\hline & & \multicolumn{2}{|l|}{ LPS } & \multicolumn{2}{|c|}{ Hypertonic saline } & \multirow{2}{*}{$\begin{array}{l}\text { Difference between the changes } \\
\text { induced by LPS and hypertonic saline } \\
(95 \% \text { CI })\end{array}$} \\
\hline & & Before & After & Before & After & \\
\hline \multicolumn{2}{|l|}{$\mathrm{n}$} & 11 & 11 & 11 & 11 & \\
\hline \multicolumn{2}{|l|}{$\mathrm{ECP}(\mu \mathrm{g} / \mathrm{l})$} & $79(55)$ & $212(187)^{\star \star}$ & $161(259)$ & $166(184)$ & $128(-11$ to 267$)$ \\
\hline \multicolumn{2}{|l|}{$\mathrm{MPO}(\mu \mathrm{g} / \mathrm{l})$} & $866(670)$ & $2123(1512)^{\star \star}$ & $2474(4333)$ & $2010(3317)$ & $1721(-821 \text { to } 4264)^{\star}$ \\
\hline \multirow[t]{2}{*}{ Eosinophils } & $\mathrm{n}$ & $0.01(0.01)$ & $0.01(0.02)$ & $0.01(0.01)$ & $0.01(0.01)$ & $0(-0.01$ to 0.02$)$ \\
\hline & $\%$ & 0.6 & 0.6 & 0.6 & 0.8 & $-0.2(-1.2$ to 0.9$)$ \\
\hline \multirow[t]{2}{*}{ Lymphocytes } & $\mathrm{n}$ & $0.04(0.03)$ & $0.09(0.05)^{\star}$ & $0.07(0.05)$ & $0.04(0.02)^{\star}$ & $0.07(0.04 \text { to } 0.1)^{\star \star}$ \\
\hline & $\%$ & 3.5 & 4.1 & 4.2 & $2.8^{\star \star}$ & $1.9(0.9 \text { to } 3.0)^{\star \star}$ \\
\hline \multirow[t]{2}{*}{ Macrophages } & $\mathrm{n}$ & $0.95(0.53)$ & $0.84(0.38)$ & $0.89(0.40)$ & $0.68(0.24)$ & $0.1(-0.3$ to 0.5$)$ \\
\hline & $\%$ & 71.7 & $40.4^{\star \star}$ & 58.5 & 50.9 & $-23.6(-36.5 \text { to }-10.7)^{\star \star}$ \\
\hline \multirow[t]{2}{*}{ Neutrophils } & $\mathrm{n}$ & $0.34(0.39)$ & $1.38(1.15)^{\star \star}$ & $0.61(0.47)$ & $0.72(0.53)$ & $0.9(0.3 \text { to } 1.6)^{\star \star}$ \\
\hline & $\%$ & 21.6 & $53.3^{\star \star}$ & 34.6 & 43.6 & $22.7(9.0 \text { to } 36.4)^{\star \star}$ \\
\hline \multirow[t]{2}{*}{ Respiratory epithelial cells } & $\mathrm{n}$ & $0.04(0.02)$ & $0.04(0.02)$ & $0.03(0.02)$ & $0.03(0.01)$ & $0.01(0$ to 0.03$)$ \\
\hline & $\%$ & 3.2 & $2.0^{\star}$ & 2.1 & 2.1 & $-1.2(-2.4$ to 0.06$)$ \\
\hline
\end{tabular}

$\mathrm{ECP}=$ eosinophilic cationic protein $\mathrm{MPO}=$ myeloperoxidase

${ }^{\star} \mathrm{p}<0.05 ;{ }^{\star \star} \mathrm{p}<0.01$. 
Table 3 Mean (SD) spirometric values before and 24 hours after inhalation of $40 \mu \mathrm{g}$ lipopolysaccharide (LPS) or hypertonic saline

\begin{tabular}{|c|c|c|c|}
\hline & Before & After & Difference (95\% CI) \\
\hline \multicolumn{4}{|l|}{ LPS: } \\
\hline $\mathrm{n}$ & 20 & 20 & \\
\hline $\mathrm{FEV}_{1}(\mathrm{l})$ & $4.04(0.82)$ & $3.97(0.77)^{\star}$ & $0.07(0.02$ to 0.12$)$ \\
\hline $\mathrm{FEV}_{1}(\%$ predicted $)$ & $105(10)$ & $103(11)^{\star \star}$ & $1.8(0.7$ to 2.9$)$ \\
\hline FVC (1) & $4.81(1.02)$ & $4.72(0.97)^{\star \star}$ & $0.09(0.04$ to 0.14$)$ \\
\hline FVC (\% predicted) & $106(13)$ & $104(13)^{\star \star}$ & $2(0.9$ to 3.0$)$ \\
\hline $\mathrm{FEV}_{1} / \mathrm{FVC}(\%)$ & $84(5)$ & $84(5)$ & $0.2(-0.5$ to 0.9$)$ \\
\hline \multicolumn{4}{|l|}{ Hypertonic saline: } \\
\hline $\mathrm{n}$ & 11 & 11 & \\
\hline $\mathrm{FEV}_{1}(1)$ & $3.63(0.60)$ & $3.62(0.54)$ & $0.01(-0.06$ to 0.08$)$ \\
\hline $\mathrm{FEV}_{1}(\%$ predicted $)$ & $102(13)$ & $102(13)$ & $0.3(-1.7$ to 2.2$)$ \\
\hline FVC (1) & $4.27(0.52)$ & $4.27(0.50)$ & $0(-0.08$ to 0.08$)$ \\
\hline FVC ( $\%$ predicted) & $102(12)$ & $102(12)$ & $-0.09(-2.3$ to 2.1$)$ \\
\hline $\mathrm{FEV}_{1} / \mathrm{FVC}(\%)$ & $85(7)$ & $85(7)$ & $0.2(-1.2$ to 1.6$)$ \\
\hline
\end{tabular}

$\mathrm{FEV}_{1}=$ forced expiratory volume in one second; $\mathrm{FVC}=$ forced vital capacity. ${ }^{\star} \mathrm{p}<0.05,{ }^{\star \star} \mathrm{p}<0.01$ whom symptoms were reported after the inhalation of LPS, the symptoms developed after 4-6 hours and persisted for 6-8 hours.

There were relationships between MPO levels in the serum and joint pains and unusual tiredness after the inhalation of LPS $\left(r_{\mathrm{xy}}=0.43\right.$; $\mathrm{p}=0.05$ and $r_{\mathrm{xy}}=0.43 ; \mathrm{p}=0.05$, respectively).

Inhalation of hypertonic saline alone did not cause any increase in the number of reported symptoms (data not shown).

\section{Discussion}

The study included only a small number of subjects, but each subject was investigated before and after the inhalation of endotoxin and hypertonic saline, acting as their own controls. This increased the possibility of finding exposure related effects. The time after exposure (24 hours) when blood and induced sputum samples were collected was chosen on the basis of results from previous experiments. An increased level of CRP in blood has been reported 24 hours after exposure in subjects challenged with LPS. ${ }^{9}$ In animal experiments the invasion of neutrophils in the airways peaks at 24 hours after exposure to endotoxin..$^{15}$ The dose of LPS used in this study was chosen as it corresponds to the suggested threshold for inducing clinical symptoms, ${ }^{5}$ while $20 \mu \mathrm{g}$ of inhaled LPS was not found to induce any symptoms. $^{9}$

The results demonstrated several effects after the inhalation of LPS in terms of inflammatory markers and cells, spirometric values, and symptoms. The amounts of MPO and ECP in the sputum were significantly increased after challenge with LPS. There were also relationships between MPO and ECP levels in the sputum. This suggests the presence of an acute inflammation in the airways, involving both neutrophils and eosinophils.

Increased levels of ECP and MPO in induced sputum have been found in previous studies of subjects exposed to LPS ${ }^{10}$ and in other forms of airways inflammation. Increased levels of ECP and MPO were found in bronchial lavage fluid samples from patients with chronic bronchitis. ${ }^{16}$ Higher concentrations of ECP in the sputum of symptomatic asthmatic patients have been reported, ${ }^{17}$ as well as a correlation between sputum levels of ECP and airflow obstruction. ${ }^{18}$ Increased amounts of ECP and MPO in serum compared with a control group were recently reported in a work environment with organic dusts. ${ }^{19}$ This suggests that ECP and MPO are markers of a non-specific inflammation.

The number of neutrophils was increased after the challenge with LPS, both in blood and in sputum. These results are similar to those previously reported by Michel et al. ${ }^{10}$ The ratio of MPO to neutrophils was decreased after inhalation of LPS, suggesting that an increase in the number of neutrophils does not necessarily cause a corresponding increase in MPO.

The mechanisms of action may be explained as follows. After inhalation LPS induces a series of intracellular changes in macrophages that can be collectively referred to as activation. 
This activation results in the production of chemotactic factors. It has been shown that the neutrophil invasion in the lung results from the secretion of chemotactic agents by alveolar macrophages. ${ }^{20}$ Endotoxin induced activation of macrophages also results in increased production of lysosomal enzymes and the production of different cytokines such as interleukin 1 (IL-1) and tumour necrosis factor $\alpha$ $(\mathrm{TNF}-\alpha)$, as well as increased production of oxygen metabolites such as superoxide anion, $\mathrm{O}_{2}^{-} \cdot{ }^{2122}$

Beyond exerting effects in the exposure site itself - that is, the lung-inhaled LPS may influence the central nervous system. This was shown in the study by general symptoms in terms of fatigue, headache, and heaviness in the head. Fever, chills, and malaise can be caused by bacterial endotoxins or dusts containing endotoxin. ${ }^{23}$ The fever causing effect of LPS is thought to be mediated by TNF- $\alpha$ activity on the hypothalamus, and LPS can cause activation of cerebral catecholamine and serotonin metabolism. ${ }^{24}$ TNF- $\alpha$ has been found in blood after LPS inhalation. ${ }^{25}$ The mechanism responsible for systemic effects after LPS inhalation might be the secretion of TNF- $\alpha$ or other mediators from activated macrophages in the lung.

A major goal of the study was to investigate the effects of LPS in the airways and to determine whether the inhalation of hypertonic saline as required in the induced sputum technique influenced the results after LPS inhalation. For ethical reasons we did not use a double blind design, in order to be able to supervise the subjects appropriately after the exposures. For the end points used (spirometric data, cells and inflammatory markers in blood and induced sputum) it is unlikely that the absence of a double blind approach could have influenced the results. With regard to symptoms, there is obviously some danger of an underestimation of the reported symptoms after inhalation of hypertonic saline alone as well as an overestimation after LPS inhalation but, on the other hand, the symptoms were classic and have been described in previous studies. $^{5}$

To assess inflammation in the airways, bronchoalveolar lavage can be used as in previous studies ${ }^{8}$ but it represents an invasive and complicated clinical procedure, not suitable for field conditions or for investigating a larger number of subjects. The induced sputum technique represents a compromise. The sputum induction technique with inhalation of hypertonic saline has been used by other researchers, and reproducible results of cellular and soluble markers have been obtained within six days ${ }^{26}$ and two days. ${ }^{27}$ Significant differences in the inflammatory response after inhalation of LPS compared with saline have previously been reported. ${ }^{10}$

Five samples containing more than $50 \%$ squamous epithelial cells were excluded from the analyses, which is not unusually high when working with induced sputum. In this study the first five samples had to be discarded because of cell lysis. When the final concentration of
DTT was decreased to $3.25 \mathrm{mM}$ the number of acceptable samples increased and was also high in another recently published study $(85 \%){ }^{28}$ This shows that the technique is valid.

Theoretically, the hypertonic saline used to induce sputum could by itself cause effects. In this study no significant differences (except for the significantly lower number of lymphocytes in sputum) were found for spirometric data, inflammatory markers and cells in blood and induced sputum 24 hours after inhalation of hypertonic saline alone. A recent study evaluated the effects of repeated sputum inductions within 24 hours and found that the sputum differential neutrophil count and level of ECP increased significantly from the first to the second induction in 10 normal subjects and 19 subjects with asthma. ${ }^{29}$ Another recent study reported a significant increase in the percentage of neutrophils, but not in the absolute neutrophil counts, in sputum 24 hours after sputum induction in eight normal subjects. ${ }^{30}$ The total amount of hypertonic saline administered in these two studies was $51 \mathrm{ml}$ and $67.5 \mathrm{ml}$. In our study no significant effects were found 24 hours after inhalation of hypertonic saline alone, but the total amount of hypertonic saline administered was $20 \mathrm{ml}$. It is likely that the magnitude of the effect of sputum induction is related to the dose of hypertonic saline given.

The numbers of lymphocytes in sputum were significantly increased after inhalation of LPS and significantly decreased after inhalation of hypertonic saline alone. The reason for the decrease in the number of lymphocytes after hypertonic saline inhalation is not known at present.

In conclusion, the results show that inhalation of LPS causes an acute airways inflammation as indicated by increased amounts of inflammatory markers in sputum and an increase in the prevalence of respiratory symptoms. It also causes general effects as shown by an increase in the prevalence of general symptoms and changes in inflammatory markers in the blood. The changes in cells and inflammatory markers were more pronounced in the sputum than in the blood, which suggests that sputum is more relevant for assessing the presence of airways inflammation after inhalation of endotoxin or organic dusts containing endotoxin. The inhalation of hypertonic saline used to induce sputum did not significantly interfere with the results found after LPS inhalation.

This study was supported by the Swedish Work Environment Fund (contract 95-0287) and the European Commission (contract BMH4-CT96-0105)

1 Rylander R, Schilling RSF, Pickering CAC, et al. Effects after acute and chronic exposure to cotton dust: the Manchester criteria. Br F Ind Med 1987;44:577-9.

2 Schwartz DA, Thorne PS, Yagla SJ, et al. The role of endotoxin in grain dust induced lung disease. Am F Respir Crit Care Med 1995;152:603-8.

3 Rylander R, Haglind P. Airborne endotoxins and humidfiers disease. Clin Allergy 1984;14:109-12.

4 Rylander R, Jacobs RR, eds. Endotoxins in the environment: a criteria document. Int f Occup Environ Health 1997;3:S1S48.

5 Rylander R, Bake B, Fisher JJ, et al. Pulmonary function and symptoms after inhalation of endotoxin. Am Rev Respir Dis $1989 \cdot 140 \cdot 981-6$. 
6 Herbert A, Carvalheiro MF, Rubenowitz E, et al. Reduction of alveolar-capillary diffusion after inhalation of endotoxin of alveolar-capillary diffusion after inhalatio
in normal subjects. Chest 1992;102:1095-8.

7 Michel O, Duchateau J, Sergysels R. Effect of inhaled endotoxin on bronchial reactivity in asthmatic and normal subjects. F Appl Physiol 1989;66:1059-64.

8 Sandström T, Bjermer L, Rylander R. Lipopolysaccharide (LPS) inhalation in healthy subjects increases neutrophils, lymphocytes and fibronectin levels in bronchoalveolar lavage fluid. Eur Respir f 1992;5:992-6.

9 Michel O, Duchateau J, Plat G, et al. Blood inflammatory response to inhaled endotoxin in normal subjects. Clin Exp Allergy 1995;25:73-9.

10 Michel O, Nagy AM, Schroeven M, et al. Dose-response relationship to inhaled endotoxin in normal subjects. $A m \mathcal{F}$ Respir Crit Care Med 1997;156:1157-64.

11 Matricardi PM, Nisini R, Pizzolo JG, et al. The use of Phadiatop 7 in mass-screening programmes of inhalant allergies: advantages and limitations. Clin Exp Allergy 1990; 20:151-5.

12 Pin I, Gibson PG, Kolendowicz R, et al. Use of induced sputum cell counts to investigate airway inflammation in asthma. Thorax 1992;47:25-9.

13 Knudson RJ, Lebowitz MD, Holberg CJ, et al. Changes in normal maximal expiratory flow-volume curve with growth and aging. Am Rev Respir Dis 1983;127:725-34.

14 Rylander R, Peterson Y, Donham KJ. Questionnaire evaluating organic dust exposure. Am $\mathcal{F}$ Ind Med 1990;17 $121-6$.

15 Venaille T, Snella MC, Holt P, et al. Cell recruitment into lung wall and airways of conventional and pathogen-free guinea pigs after inhalation of endotoxin. Am Rev Respir Dis 1989;139:1356-60.

16 Riise GC, Ahlstedt S, Larsson S, et al. Bronchial inflammation in chronic bronchitis assessed by measurement of cell products in bronchial lavage fluid. Thorax 1995;50:360-5.

17 Konno S, Gonokami Y, Kurokawa M, et al. Cytokine concentrations in sputum of asthmatic patients. Int Arch concentrations in sputum of as

Allergy Immunol 1996;109:73-8.
18 Virchow JC, Hölscher U, Virchow C. Sputum ECP levels correlate with parameters of airflow obstruction. Am Rev Correlate with parameters
Respir Dis 1992;146:604-6.
19 Rylander R, Thorn J, Attefors R. Airways inflammation among workers in a paper industry. Eur Respir $\mathcal{F} 1998$ (in among

20 Snella MC. Production of a neutrophil chemotactic factor by endotoxin stimulated macrophages in vitro. $B r \mathcal{F}$ Exp Pathol 1986;67:801-7.

21 Hsieh V, Amoruso-Marchat B, Rylander R, et al. Oxygen metabolites from lavage and interstitial lung cells after inhalation of endotoxin in guinea pigs. Int Arch Allergy Immunol 1994;104:42-7.

22 de Rochemonteix-Galve B, Amoruso-Marchat B, Dayer JM, et al. Tumor necrosis factor and interleukin-1 activities in free lung cells after single and repeated inhalation of bactefree lung cells after single and repeated inhalation
rial endotoxin. Infect Immun 1991;59:3646-50.

23 Von Essen S, Robbins RA, Thompson AB, et al. Organic dust toxic syndrome: an acute febrile reaction to organic dust exposure distinct from hypersensitivity pneumonitis. $\mathcal{F}$ Toxicol Clin Toxicol 1990;28:389-420.

24 Dunn AJ. Endotoxin-induced activation of cerebral catecholamine and serotonin metabolism: comparison with interleukin-1. F Pharmacol Exp Ther 1992;261:964-9.

25 Michel O, Ginanni R, Le-Bon B, et al. Inflammatory response to acute inhalation of endotoxin in asthmatic patients. Am Rev Respir Dis 1992;146:352-7.

26 Pizzichini E, Pizzichini MM, Efthimiadis A, et al. Indices of airway inflammation in induced sputum: reproducibility airway inflammation in induced sputum: reproducibility and validity of cell and fluid-phase me
Respir Crit Care Med 1996;154:308-17.

27 in't Veen JC, de Gouw HW, Smits HH, et al. Repeatability of cellular and soluble markers of inflammation in induced sputum from patients with asthma. Eur Respir $\mathcal{F}$ 1996;9: 2441-7.

28 Thorn J, Beijer L, Rylander R. Airways inflammation and glucan exposure among household waste collectors. Am f Ind Med 1998;33:463-70.

29 Holtz O, Richter K, Jörres RA, et al. Changes in sputum composition between two inductions performed on consecutive days. Thorax 1998;53:83-6.

30 Nightingale JA, Rogers DF, Barnes PJ. Effect of repeated sputum induction on cell counts in normal volunteers.
Thorax 1998;53:87-90. 